\title{
Location of Geminiviruses in the Whitefly Bemisia tabaci (Homoptera: Aleyrodidae)
}

\author{
W. B. Hunter, University of Florida, Gulf Coast Research and Education Center, 500760 St. E., Bradenton $34203-$ \\ 9324; E. Hiebert, University of Florida, Plant Pathology Department, 1453 Fifield Hall, Gainesville 32611-0680; S. \\ E. Webb, University of Florida, Central Florida-REC, 5336 University Ave., Leesburg 34748-8232; J. H. Tsai, \\ University of Florida, Ft. Lauderdale-REC, 3205 S.W. College Ave., Ft. Lauderdale 33314-7700; and J. E. Polston, \\ University of Florida, Gulf Coast Research and Education Center, Bradenton 34203
}

\begin{abstract}
Hunter, W. B., Hiebert, E., Webb, S. E., Tsai, J. H., and Polston, J. E. 1998. Location of geminiviruses in the whitefly Bemisia tabaci (Homoptera: Aleyrodidae). Plant Dis. 82:1147-1151.

The location of tomato mottle virus (ToMoV) and cabbage leaf curl virus (CabLCV) (Geminiviridae, genus Begomovirus) in the whitefly vector Bemisia tabaci B-biotype (Homoptera: Aleyrodidae) was elucidated using a novel technique incorporating indirect immunofluorescent labeling in freshly dissected whiteflies. Begomoviruses were visualized in the whitefly by indirect-fluorescent-microscopy. Polyclonal and monoclonal primary antibodies were used to successfully detect both ToMoV and CabLCV. Both begomoviruses were located in the anterior region of the midgut and filter-chamber of adult whiteflies, with ToMoV detected in the salivary glands. CabLCV was detected at a greater frequency than ToMoV, with a positive detection of $16 \%$ (89 out of 560) for CabLCV and 3\% (25 out of 840 ) for ToMoV. Possible sites involved in geminivirus transport from the gut lumen of whiteflies into the hemocoel were located in the filter-chamber and anterior portion of the midgut. The location of these begomoviruses suggests a possible scenario of virus movement through the whitefly, which is discussed.
\end{abstract}

Additional keywords: Bemisia argentifolii, tomato

Geminiviruses are plant viruses with a circular, single-stranded DNA genome encapsidated in a geminate capsid (paired icosahedral units). These economically important whitefly-transmitted viruses are in the family Geminiviridae, genus Begomovirus. The majority of begomoviruses are transmitted by whiteflies in the Bemisia tabaci complex $(2,8,13)$, which includes Bemisia tabaci (Gennadius) B-biotype. Surprisingly, little is known about the virus-vector relationships that allow these viruses to be transmitted. One important aspect that has not yet been determined is the pathway of begomoviruses through the whitefly, which is due in part to problems encountered when attempting to visualize these viruses within insect tissues. The understanding gained from studies on the biological interactions between the begomoviruses and their vectors will bring us closer to the development of novel management strategies against these widespread and economically important plant

Corresponding author: W. B. Hunter

E-mailwhunter@ao.net

Accepted for publication 7 July 1998.

Publication no. D-1998-0803-01R

(C) 1998 The American Phytopathological Society viruses. The purpose of this study was to elucidate the location of two begomoviruses in their whitefly vector.

\section{MATERIALS AND METHODS}

Whiteflies. All whiteflies examined were adults from laboratory colonies of Bemisia tabaci B-biotype (also described as $B$. argentifolii Bellows and Perring [3]) maintained at the Central Florida Research and Education Center in Leesburg. Confirmation of species and biotype were performed by T. M. Perring, University of California, Riverside. Insects were reared in cages on collard, Brassica oleracea L. var. acephala 'Georgia Southern', a nonhost of tomato mottle virus (ToMoV), at 23 to $27^{\circ} \mathrm{C}$ with a photoperiod of $16 \mathrm{~h}$ light, 8 $\mathrm{h}$ dark. Begomovirus acquisitions were either from tomato, Lycopersicon esculentum L. 'Florida Lanai', infected with ToMoV, or from cabbage, Brassica oleracea L. var. capitata, infected with cabbage leaf curl virus (CabLCV). Whiteflies were examined primarily by light microscopy, but transmission- (TEM) and scanning-electron microscopy (SEM) were performed to elucidate or confirm structures and location within the insects. Samples for SEM and TEM were prepared as in Hunter et al. (11). Whiteflies prepared for SEM were dehydrated in an ethanol series 50, 70, 80, 95, with three changes at $100 \%$. Specimens were then critical-point dried and mounted on electron microscopy stubs with double sticky mounts (Avery Dennison, Spot-o-glue, Schaumburg, IL) and sputter-coated for observation. Whiteflies prepared for TEM were fixed for $8 \mathrm{~h}$ on a rotor in $2 \%$ glutaraldehyde, $2 \%$ paraformaldehyde solution ( $0.1 \mathrm{M}$ phosphate buffer, $\mathrm{pH}$ 7.4), followed by three 15-min washes with buffer, with postfixation overnight in $1 \%$ osmium-tetroxide. Specimens were then washed with buffer three times, dehydrated in an ethanol series (50 to $95 \%$ ) over a 3-hour period and embedded through transitional stages into LRWhite resin (Ted Pella, Inc., Redding, CA) $(30,50,100 \%)$ mixed with $95 \%$ ethanol. Blocks were sectioned and placed on formvar-coated nickel grids, 50 mesh, and stained with uranyl-acetate ( $2 \%$ aqueous, $20 \mathrm{~min})$ and lead citrate $(6 \mathrm{~min})$. Thick sections were transferred by a wire loop to a glass slide to be dried and stained with Azure II for 10 to $15 \mathrm{~s}$, rinsed with water, and counterstained with basic fuchsin for 30 to $40 \mathrm{~s}$, rinsed again, and mounted with Permount (Fisher Scientific, Pittsburgh, PA).

Preparation of whiteflies for indirect fluorescent labeling. Collection. Adult whiteflies which had been given an acquisition access feeding period (AAP) of 5 to 6 days on either infected tomato or infected cabbage plants were removed from the infected plants and put on a healthy nonvirus host plant (on collards after ToMoV acquisition from tomato, or on tomato after CabLCV acquisition from cabbage) for 24 to $48 \mathrm{~h}$ prior to being collected for testing. Plants were grown in 15.5 -cm-diameter plastic pots and were covered with netting. Whiteflies were collected in a manner that caused minimal damage to the insects. The open end of a large test tube was inserted at the top of the netting. The plant with whiteflies was then covered with a black cloth, leaving the test tube exposed. The whiteflies, being attracted to the light, moved into the tube and were collected.

Antibodies. Monoclonal antibody 3F7 was evaluated and shown to react efficiently in Western blot and enzyme-linked immunosorbent assay (ELISA) for the detection of a wide range of geminiviruses (Abutilon mosaic; isolates of bean golden mosaic virus [BGMV] from Puerto Rico, Homestead in Florida, Brazil, Dominican 
Republic, and the Caribbean; Euphorbia mosaic; Rhynchosia mosaic; squash leaf curl; soybean yellow mosaic; Macroptilium lathyroides isolate in Florida; and ToMoV).
Monoclonal antibody 2G5 reacted only with BGMV isolates from Dominican Republic, Guatemala, and Puerto Rico. The polyclonal antibodies, 1110,1175 , and
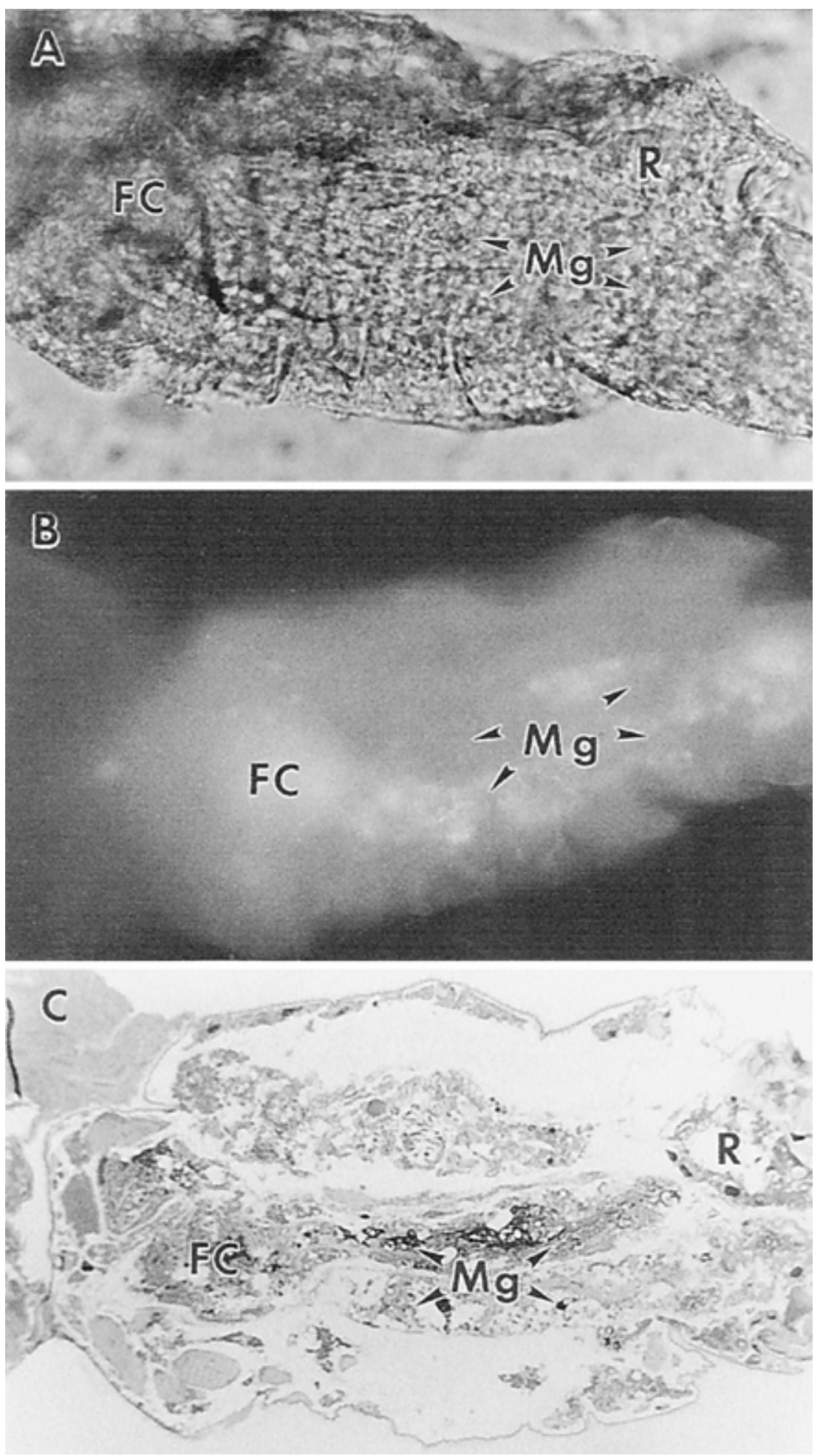

Fig. 1. (A) Light micrograph of adult whitefly, Bemisia tabaci, abdomen after a 6-day acquisition access period on cabbage infected with cabbage leaf curl geminivirus. Same abdomen in photos B and $\mathrm{C}$, filter-chamber $(\mathrm{FC})$, midgut $(\mathrm{Mg})$, rectum $(\mathrm{R})$. All photos approximately $\times 150$. (B) UV micrograph showing geminivirus detected in the whitefly filter-chamber (FC) and midgut intestine (Mg) using indirect fluorescent-conjugated antibody labeling. (C) Light micrograph of a thick section made after whitefly was photographed in B. Sample was then fixed, embedded, sectioned, and stained. Section showing that fluorescence was located in the filter-chamber (FC) and midgut intestine $(\mathrm{Mg})$.

1200 , reacted to a wide range of whiteflytransmitted begomoviruses (1). A detailed description of the monoclonal antibodies has been reported (6).

Dissection of whiteflies. Live whiteflies collected in glass test tubes were immobilized by placing them at $-20^{\circ} \mathrm{C}$ for several minutes. Six to eight whiteflies were removed one at a time with a small brush from the test tube and placed on a glass slide upon which a circle had been drawn with a PAP-pen (Zymed Laboratories, S. San Francisco, CA), a hydrophobic solution that, when dry, confines solutions within the circle. Whiteflies were manipulated while being observed with a Wild dissection scope (Wild, Germany). Before the whiteflies recovered from the cold, a small drop of clear fingernail polish was placed in the middle of the PAP circle on the slide, the whiteflies were placed either ventral side down or on their sides in the polish with the wings spread. The samples were then set aside so that the polish could dry, making sure that the whiteflies did not dry out. When the polish had dried, the whiteflies were covered with $10 \mathrm{mM}$ phosphate buffer saline (PBS), pH 7.4, (Sigma Co., P-3813, St. Louis, MO) until all samples had been mounted and subsequently dissected using a razor and fine-tip forceps. Dissection in this manner exposed the intact digestive tract and other organelles. This allowed the labeling of antigenic sites present on the inside of the insect, but on the outside membranes of the digestive tract and salivary glands.

Dissected and mounted samples were then blocked for $30 \mathrm{~min}$ with Protein Blocking Agent (PBA) (Tris buffer, bovine immuno-globulin, albumin gelatin, and sodium azide) to which healthy goat normal serum was added (at 1:1,000). The PBA was blotted off, and the appropriate primary antibody was applied (diluted $1: 1,000$ in $10 \mathrm{mM}$ PBS, pH 7.4) (either rabbit polyclonal 1110,1175 , or 1200 , or mouse monoclonal $3 \mathrm{~F} 7$ or $2 \mathrm{G} 5$ [6]) for 30 to $60 \mathrm{~min}$, followed with three washes of 15 min each with PBS. All steps starting with applications of the secondary FITCconjugated antibody (fluorescein isothiocyanate [FITC] conjugated antibody, Sigma Immuno Chemicals, St. Louis, MO) were covered with a small box to shield samples from exposure to light. The appropriate secondary FITC-conjugated antibody, either goat anti-rabbit or goat antimouse, was applied to samples for 20 to 30 min, diluted 1:1,000 in PBS. Samples were then washed three times for 15 min each in PBS buffer and once with distilled water $\left(\mathrm{dH}_{2} \mathrm{O}\right)$. Samples were then mounted in Aqua-Mount (mounting medium, antiquenching fluorescent extender, polyvinyl alcohol-vinylacetate, Polysciences, Inc., Warrington, PA). Photographs were taken with a Nikon, Fluo-Phot microscope (Nikon, Japan). Samples consisted of the following: those with no primary antibody; 
those with primary antibody but no secondary conjugated antibody; those blocked with normal goat serum or rabbit serum; and those with a primary monoclonal antibody, 2G5, which did not cross react with ToMoV or CabLCV.

Transmission efficiency. Whitefly transmission efficiency for ToMoV was conducted in earlier experiments using single adult whiteflies (123 males and 123 females) evaluated in $110-\mathrm{cm}$ cylindrical plastic cages on tomato. Viruliferous whiteflies were reared on ToMoV-infected tomato plants. Individual adults were then given a transmission access period of $72 \mathrm{~h}$ under greenhouse conditions $\left(22\right.$ to $\left.28^{\circ} \mathrm{C}\right)$ to virus-free tomato seedlings. Receptor tomato plants were evaluated for virus infection by PCR and symptomology.

\section{RESULTS}

ToMoV and CabLCV were detected in whiteflies by indirect fluorescein-conjugated antibody labeling. Begomoviruses were detected in $3 \%$ of 840 whiteflies given access to ToMoV-infected tomato and $16 \%$ of 560 whiteflies given access to CabLCV infected cabbage. Experiments on transmission efficiencies were only conducted for ToMoV. Results from four experiments conducted on single whitefly transmission efficiencies produced rates of $3.2 \%$ for females and $4.8 \%$ for males (123 females and 123 males).

The location of begomovirus in whiteflies given access to plants infected with either virus resulted in detection of positive fluorescence in the membranes that surround the filter-chamber and anterior two-thirds of the midgut intestine (Fig. 1). Whiteflies given access to healthy plants showed a faint background fluorescence (Fig. 2), but never the bright fluorescence found in positive samples (Fig. 1). There was no detection of either virus in the esophagus, foregut, later third of the midgut (the ascending intestine) where excess water would be entering from the midgut wall contacting the filter-chamber, or in the hindgut (ileum or rectum). The salivary gland membrane of insects given an acquisition access period on ToMoVinfected plants also showed positive fluorescence (Fig. 3); however, this was not observed for those whiteflies fed on CabLCV-infected plants. Sufficient information to explain this difference was lacking. A model showing the sites that resulted in positive detection of both begomoviruses in the whitefly are shown (Fig. 4).

Labeling fresh tissues bypassed some of the common problems associated with fixing, embedding, sectioning, and immuno-gold labeling geminivirus in whitefly tissues. Some of these problems were the nonspecific immuno-gold labeling in thin sections, which resulted in inconclusive virus detection results. Whitefly crystalline proteins found in the legs also labeled readily by immuno-gold techniques (data not shown). Nonspecific labeling of the egg yolk proteins in healthy and viruliferous whiteflies were also observed when using immuno-gold labeling techniques (data not shown).

\section{DISCUSSION}

Positive detection by indirect immunofluorescent labeling was obtained in whiteflies in situ for both ToMoV and CabLCV. These are the first observations that provide evidence that the filter-chamber and anterior region of the midgut intestine are the likely sites of Begomovirus entry into the whitefly hemocoel. We also provide evidence of Begomovirus within the salivary gland membrane of $B$. tabaci (Fig. 3). Information to explain the differ- ences between the detection of ToMoV and CabLCV in whitefly salivary glands is absent. However, these differences in detection may be associated with differences in the rates at which these two viruses move through the whitefly-vector system; different rates would allow for a difference in detection at the salivary gland membrane by producing different windows of opportunity for viral detection within these tissues. There are probably differences in whitefly feeding behavior on these two different host plants, or perhaps the difference was due to virus-titer differences in the two viral host plants (tomato versus cabbage). Further studies are warranted to more closely examine such differences between these geminiviruses and their vectors.
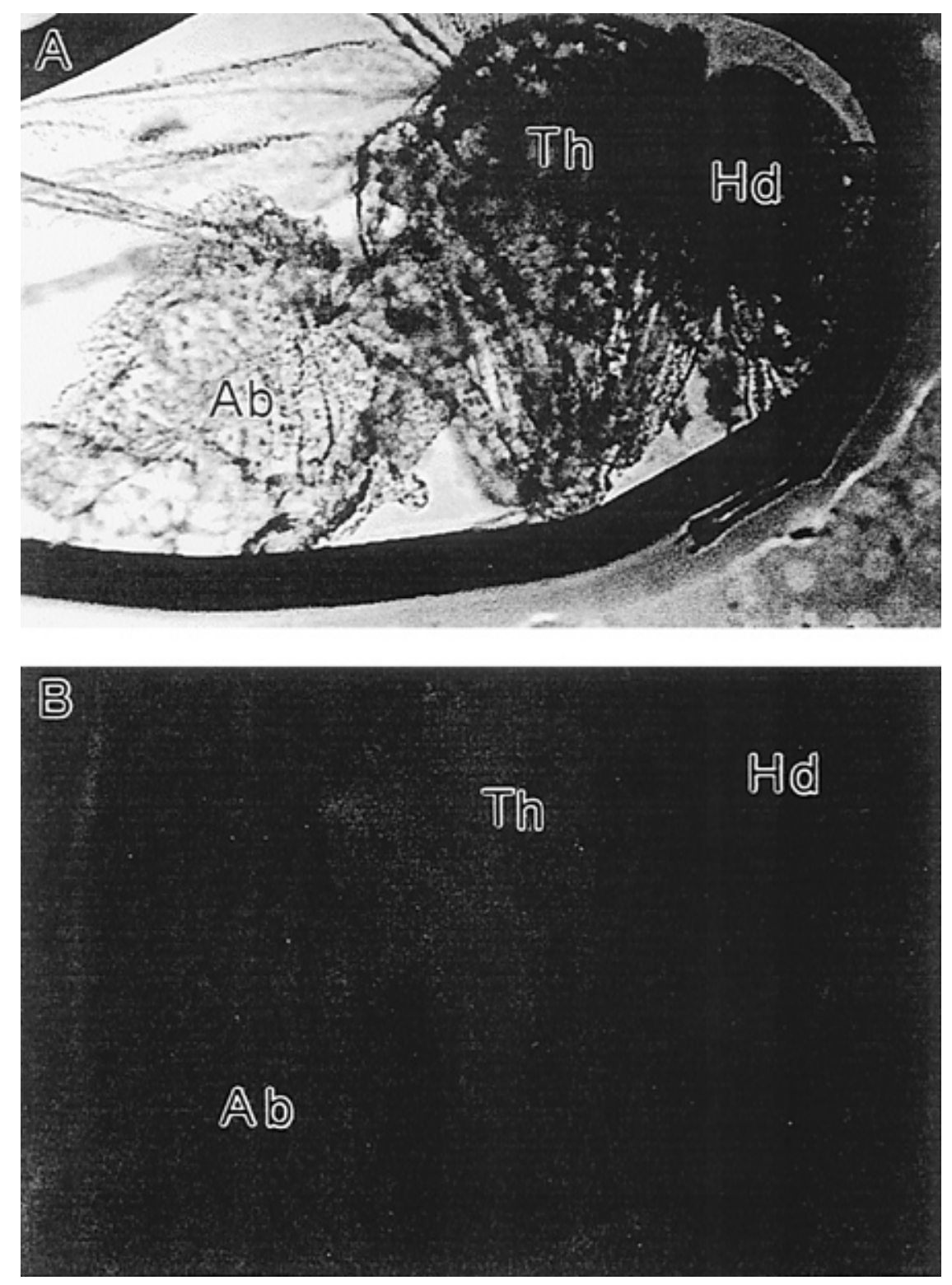

Fig. 2. (A) Light micrograph of an adult whitefly from the control group fed on a healthy plant Whitefly has been dissected and treated the same as whiteflies fed on a virus-infected plant. (B) UV micrograph showing level of background fluorescence detected in control whiteflies. Key for both photos: head (Hd), thorax (Th), abdomen (Ab). Approximately $\times 200$. 

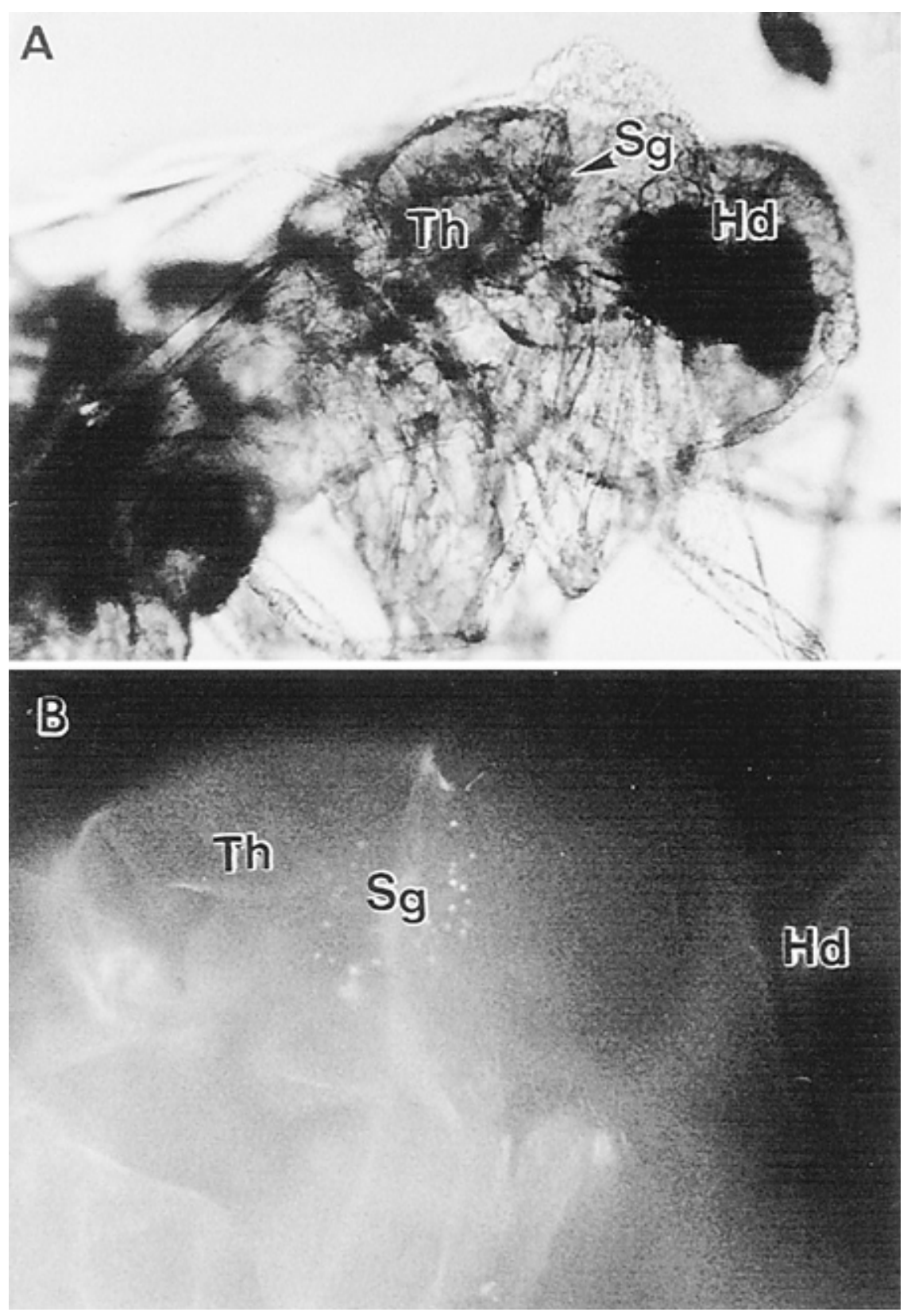

Fig. 3. (A) Light micrograph of adult whitefly, Bemisia tabaci, after a 5-day acquisition access period on a tomato mottle virus (ToMoV) infected plant, processed for immunofluorescent labeling. Cut made posterior of pronotum. Head $(\mathrm{Hd})$, thorax $(\mathrm{Th})$, salivary gland $(\mathrm{Sg})$. Approximately $\times 200$. (B) UV micrograph showing detection of geminivirus, ToMoV, localized sites of virus in salivary gland $(\mathrm{Sg})$. Head $(\mathrm{Hd})$, thorax $(\mathrm{Th})$. Approximately $\times 400$.

These findings correspond with descriptions of maize streak virus movement in Cicadulina species of leafhoppers (13). Furthermore, our findings support in part the descriptions of circulative Begomovirus movement as found for squash leaf curl virus (SLCV) in the silverleaf whitefly, $B$. tabaci (10).

It is still unclear whether some begomoviruses replicate in their whitefly vector. Replication of tomato yellow leaf curl virus (TYLCV) in the whitefly vector has been suggested (14); results indicated that there was an increase of TYLCV titer over time. Other reports, although inconclusive, have suggested that SLCV might replicate through the insect body. Many insect viruses enter insect cells by receptor-mediated endocytosis (9), and similar mechanisms may be operating in the $\mathrm{Be}$ gomovirus-whitefly system. More research is needed before the virus-vector cell interactions regulating Begomovirus acquisition by whiteflies is understood.

With the information gathered, one possible model for Begomovirus movement through the whitefly vector is proposed (Fig. 4). Virus is ingested along with plant fluids into the esophagus and foregut. As food enters the filter-chamber, excess water is shunted to the ileum of the hindgut (12); thus nutrients and begomoviruses become concentrated in the filter-chamber. Begomoviruses may adsorb to specific sites on the alimentary membranes here or at sites along the anterior region of the midgut, where labeling occurred; however, the exact mode of virus entry into cells is unknown. Begomoviruses then move out of these cells (detected by indirect labeling) into the insect hemolymph (16), eventually invading the salivary glands (4). It is unknown in what form begomoviruses move through the whitefly system, whether as complete virions or as an uncoated viral DNA-protein complex.

Further research on begomoviruses in whitefly hemolymph is needed before such questions can be answered. However, it is likely that once begomoviruses reach the salivary glands, they pass through the salivary gland membrane (15). Within the salivary glands, the virus passes along small ductules to the salivary ducts, being passed out of the insect with the saliva (15) and into the plant cells where the insect is feeding. Once the virus is in a susceptible host plant, it multiplies, and disease ensues.

With the implication of the filter-chamber and midgut membranes as Begomovirus entry sites, future research needs to examine the acquisition of different begomoviruses and the role of the filter-chamber, midgut, and salivary gland membranes as selective barriers to Begomovirus acquisition and transmission.

\section{ACKNOWLEDGMENTS}

Florida Agricultural Experiment Stations Journal Series Paper R-06362. We thank Maureen Petersen and Brian Peyser for technical and darkroom assistance. This research was supported in part by BARD-US Grant IS-1813-90, Florida Agricultural Experiment Station, USDA Cooperative Agreement Grant 92-34135-7456, and the University of Florida Support Services, Electron Microscope Core Facility, Center for Structural Biology.

\section{LITERATURE CITED}

1. Abouzid, A. M., Purcifull, D. E., Polston, J. E., Beckham, K. A., Crawford, W. E., Petersen, M. A., and Hiebert, E. 1998. Serological studies using polyclonal antiserum prepared against the cabbage leaf curl geminivirus coat protein expressed in Escherichia coli. Page P-42 in: Int. Workshop Bemisia Geminiviral Dis., 2nd. USDA-ARS, 


\section{Geminivirus Transmission}

\section{in Bemisia tabaci}
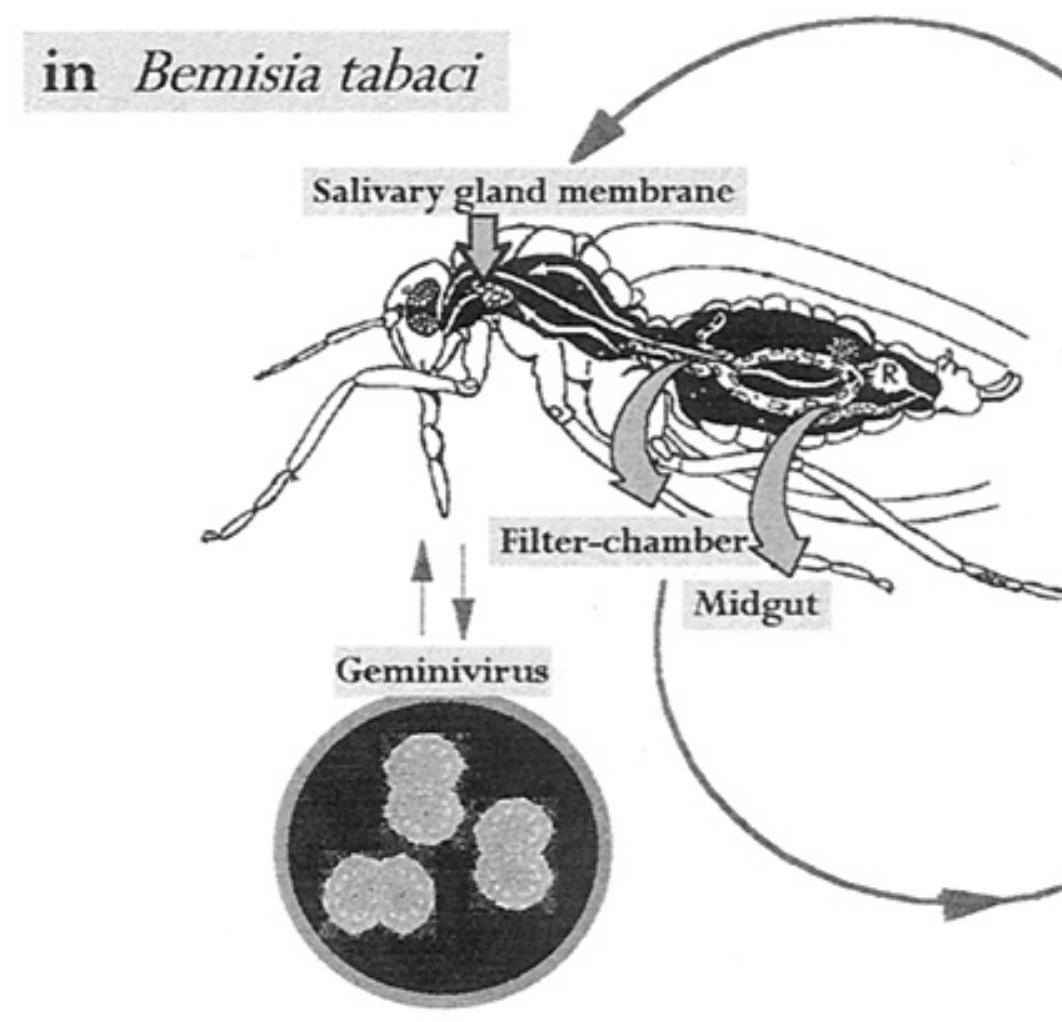